\title{
A multi-angle aerosol optical depth retrieval algorithm for geostationary satellite data over the United States
}

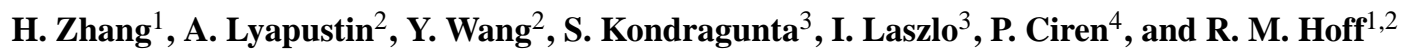 \\ ${ }^{1}$ Joint Center for Earth Systems Technology (JCET), University of Maryland Baltimore County, Suite 320, 5523 Research \\ Park Drive, Baltimore, MD 21228, USA \\ ${ }^{2}$ Goddard Earth Sciences and Technology Center (GEST), University of Maryland Baltimore County, Suite 320, 5523 \\ Research Park Drive, Baltimore, MD 21228, USA \\ ${ }^{3}$ NOAA/NESDIS/STAR, 5825 University Research Ct, College Park, MD 20740, USA \\ ${ }^{4}$ PSGS/Dell, 5825 University Research Ct, College Park, MD 20740, USA
}

Received: 29 October 2010 - Published in Atmos. Chem. Phys. Discuss.: 20 April 2011

Revised: 16 October 2011 - Accepted: 17 November 2011 - Published: 2 December 2011

\begin{abstract}
Aerosol optical depth (AOD) retrievals from geostationary satellites have high temporal resolution compared to the polar orbiting satellites and thus enable us to monitor aerosol motion. However, current Geostationary Operational Environmental Satellites (GOES) have only one visible channel for retrieving aerosols and hence the retrieval accuracy is lower than those from the multichannel polar-orbiting satellite instruments such as the Moderate Resolution Imaging Spectroradiometer (MODIS). The operational GOES AOD retrieval algorithm (GOES Aerosol/Smoke Product, GASP) uses 28-day composite images from the visible channel to derive surface reflectance, which can produce large uncertainties. In this work, we develop a new AOD retrieval algorithm for the GOES imager by applying a modified MultiAngle Implementation of Atmospheric Correction (MAIAC) algorithm. The algorithm assumes the surface Bidirectional Reflectance Distribution Function (BRDF) in the channel 1 of GOES is proportional to seasonal average MODIS BRDF in the $2.1 \mu \mathrm{m}$ channel. The ratios between them are derived through time series analysis of the GOES visible channel images. The results of AOD and surface reflectance retrievals are evaluated through comparisons against those from Aerosol Robotic Network (AERONET), GASP, and MODIS. The AOD retrievals from the new algorithm demonstrate good agreement with AERONET retrievals at several sites across the US with correlation coefficients ranges from 0.71 to 0.85 at five out of six sites. At the two western sites Railroad Valley and UCSB, the MAIAC AOD retrievals have
\end{abstract}

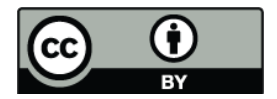

Correspondence to: $\mathrm{H}$. Zhang (hazhang@umbc.edu) correlations of 0.8 and 0.85 with AERONET AOD, and are more accurate than GASP retrievals, which have correlations of 0.7 and 0.74 with AERONET AOD. At the three eastern sites, the correlations with AERONET AOD are from 0.71 to 0.81 , comparable to the GASP retrievals. In the western US where surface reflectance is higher than 0.15 , the new algorithm also produces larger AOD retrieval coverage than both GASP and MODIS.

\section{Introduction}

Aerosols play an important role in the atmosphere by modifying radiative forcing, climate, weather, and air quality. They can affect the Earth's radiative budget by directly changing the radiation reflected from the Earth and can also indirectly change the radiative forcing by modifying the cloud properties through microphysical process (Charlson et al., 1992; Kiehl et al., 1993; Ramanathan et al., 2001; Lohmann and Feichter, 2005; Intergovernmental Panel on Climate Change, 2007). Aerosols influence other aspects in climate and weather such as precipitation (Rosenfeld et al., 2008), monsoon (Lau et al., 2008), lightening (Yuan et al., 2011), etc. In addition, aerosols also influence the air quality close to the surface and affect the human health (Pope et al., 2002, 2006; Chow et al., 2006; Pope et al., 2009). Thus, accurate measurements of aerosols can both improve our knowledge on climate change (Intergovernmental Panel on Climate Change, 2007) and improve our ability to monitor and to forecast particulate matter air quality (e.g. Al-Saadi et al., 2005; Hoff and Christopher, 2009; Hidy et al., 2009).

Published by Copernicus Publications on behalf of the European Geosciences Union. 
Many polar orbiting satellite instruments are used to measure aerosols, such as MODIS (Kaufman et al., 1997; Tanré et al., 1997; Levy et al., 2007), Multiangle Imaging Spectroradiometer (MISR) (Martonchik et al., 1998), POLarization and Directionality of the Earth's Reflectances (POLDER, Deuzé et al. (2001)) etc., but they all have low temporal resolution. For example, the widely used aerosol product from MODIS only has a twice-daily coverage from Terra and Aqua platform. Geostationary satellites can overcome this shortcoming: the National Oceanic and Atmospheric Administration (NOAA) GOES makes the monitoring of aerosols available at a higher temporal resolution over the United States with a rate of every half hour during sun-lit period (Prados et al., 2007). However, current GOES only has one visible channel that can be used for retrieving AOD, which makes the uncertainty of retrievals larger than those from MODIS that utilizes multi-spectral signal for the AOD retrieval (Prados et al., 2007).

The current operational GASP product uses 28-day composite image from channel 1 (visible channel with spectral range of $0.52-0.72 \mu \mathrm{m}$ ) to find the second darkest day at each observation time and uses it to retrieve surface reflectance. The GASP algorithm assumes that the surface reflectance does not change during the 28-day period for each observation time. To retrieve surface reflectance, AOD at the second darkest day is assumed to be 0.02 . The uncertainties of GASP originate from assumptions of aerosol model, surface reflectance, cloud/cloud shadow contamination, and calibration errors. Analysis of uncertainties from aerosol model, surface reflectance, and calibration for GOES can be found in Zhang et al. (2001): the AOD uncertainty from calibration error is about $10 \%$ for small $\mathrm{AOD}(\tau=0.5)$ and $7 \%$ for large AOD $(\tau=1.5)$, from aerosol model is $10 \%$ for small AOD ( $\tau=0.5)$ and $32 \%$ for large AOD $(\tau=1.5)$. The uncertainty in the surface reflectance retrieval may result in large error in AOD retrievals. As shown in Zhang et al. (2001), $1 \%$ error in surface reflectance can introduce $10 \%$ AOD error for small AOD $(\tau=0.5)$. In reality, we sometimes can observe $20 \%$ to $30 \%$ change in surface reflectance within 28 days, which can lead to much larger uncertainty than those from aerosol model and calibration. Several factors can contribute to the changes in surface reflectance in 28 days. First, during the 28-day period for surface reflectance retrieval, the surface property may change due to the change in the color and growing state of vegetation. Second, the surface reflectance may also be different between the day of AOD retrieval and the day of surface reflectance retrieval because of the difference in Sun-satellite geometry between these two days. Third, the existence of cloud shadow may introduce too low surface reflectance retrieval at the times when cloud shadow occurs frequently. In addition, the look-up-table (LUT) in GASP is generated from $6 \mathrm{~S}$ with Lambertian assumption. The ignorance of non-Lambertian nature of surface may generate errors in some situations. The motivation of this research is to develop a new algorithm that can retrieve surface re- flectance more accurately by reducing the period for surface reflectance retrieval. In this new method, we abandon the Lambertian assumption and make use of BRDF to model the surface property in order to reduce the uncertainty in surface reflectance retrievals.

The MAIAC algorithm is an aerosol retrieval and atmospheric correction scheme over land for MODIS data (Lyapustin and Wang, 2009; Lyapustin et al., 2011a,b). The algorithm uses time series of multi-channel images to retrieve surface BRDF and aerosol properties. The surface BRDF is first retrieved in the $2.12 \mu \mathrm{m}$ band assuming this band is not affected by aerosol. Then surface BRDF in the blue band and the red band are assumed to be proportional to that in the $2.12 \mu \mathrm{m}$ band, and the ratios are retrieved from time series analysis with the aid of a look-up-table (LUT). The benefit of this method is that it can be applied to regions where the surface reflectance relations between blue, red and SWIR band in MODIS operational retrieval algorithm (MOD04) are inaccurate. For example, MAIAC algorithm can retrieve AOD over bright surfaces such as desert where MOD04 does not have retrievals. In this paper, we modify this algorithm so that it can be applied on GOES data to retrieve surface BRDF and AOD. Since current GOES does not contain a SWIR band, we use seasonal averages of MODIS BRDF in the $2.12 \mu \mathrm{m}$ band for reference, and assume that BRDF in the GOES visible band is proportional to MODIS BRDF in $2.12 \mu \mathrm{m}$. The MAIAC algorithm can hence be applied for aerosol retrieval using GOES visible band data.

In Sect. 2, we describe the data used in this work. In Sect. 3, we describe the details of the modified MAIAC algorithm. In Sect. 4, we evaluate the retrieval results through comparisons to AERONET, GASP and MODIS retrievals. In Sect. 5, we conclude the work.

\section{Data}

\subsection{GOES data}

The current GOES satellite imager measures radiances reflected and emitted from the Earth and atmosphere in one visible channel and four infrared channels. In this study, we use channel 1 (visible channel, $0.52-0.72 \mu \mathrm{m}$ ), channel $2(3.9 \mu \mathrm{m})$ and channel $4(10.7 \mu \mathrm{m})$ radiances from GOES-12, which is located at $75^{\circ} \mathrm{W}$ above the equator. The visible channel radiances are used for surface reflectance and AOD retrieval. The visible channel and the two infrared channels radiances are used for deriving cloud masks. The spatial resolution at nadir is $1 \mathrm{~km}$ for the visible channel and is $4 \mathrm{~km}$ for the two IR channels. Since there is no on-board calibration device for the imager, the radiances are calibrated using a vicarious method (see http://www.oso.noaa.gov/goes/goes-calibration/ goes-vis-ch-calibration.htm). GOES-12 images covering continental US have a temporal resolution of half hour. 


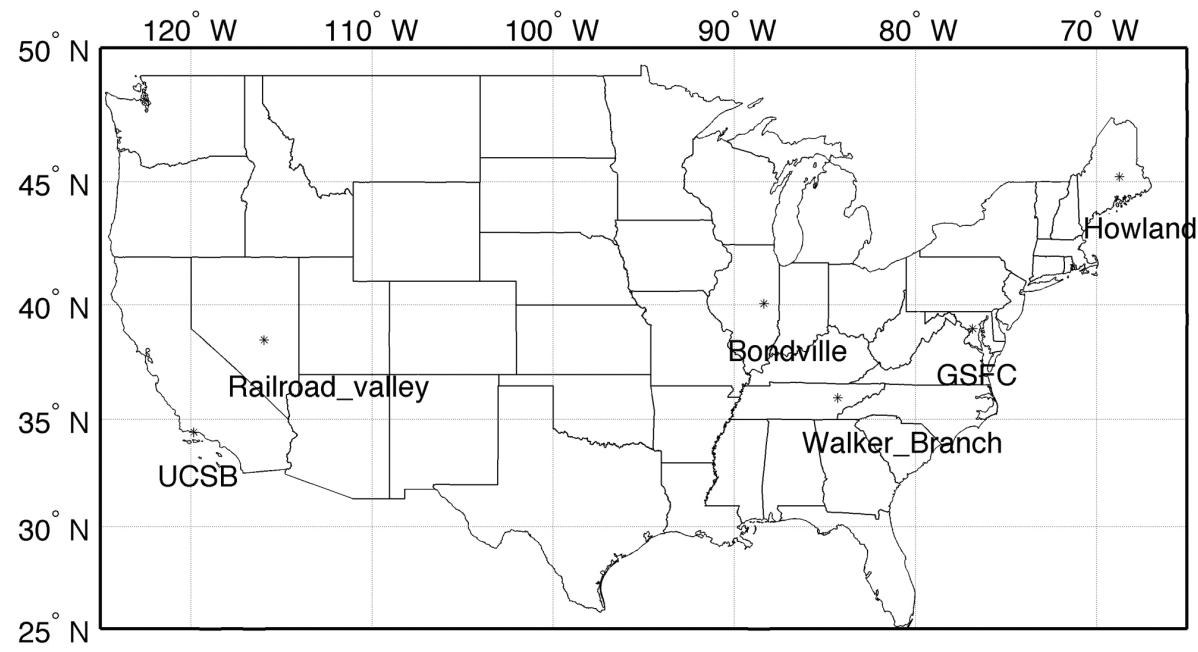

Fig. 1. Locations of the AERONET sites used for validation.

To evaluate the retrieval results of the MAIAC algorithm, we compare them with those from the current operational algorithm: GASP (Knapp et al., 2005; Prados et al., 2007). GASP provides AOD retrievals at $0.55 \mu \mathrm{m}$ with a spatial resolution of $4 \mathrm{~km}$. As mentioned above, it uses a 28-day composite image of visible channel to derive surface reflectance with an assumption of 0.02 background AOD on the second clearest day. The retrieved surface reflectance is used along with channel 1 radiances and the LUT from $6 \mathrm{~S}$ radiative transfer model to retrieve AOD. The cloud-masking algorithm is based on CLAVR (Clouds from AVHRR) algorithm from AVHRR (Advanced Very High Resolution Radiometer) (Stowe et al., 1999; Heidinger et al., 2001). GASP provides values at $0.55 \mu \mathrm{m}$ but the measurement is between $0.52 \mu \mathrm{m}$ and $0.72 \mu \mathrm{m}$. The uncertainty caused by it is the same as the uncertainty due to the choice of a fixed aerosol model, since once the aerosol model is determined, i.e. size distribution, refractive index etc, the relation between $0.55 \mu \mathrm{m}$ AOD and the GOES channel 1 TOA reflectance is determined.

\subsection{AERONET data}

AERONET (http://aeronet.gsfc.nasa.gov) is a global network for aerosol monitoring from ground stations using Sunphotometers. The quality assured level 2.0 AERONET AOD data is used for evaluating the AOD retrievals and for evaluating the surface BRDF retrievals from GOES data. Since the AERONET AOD retrievals have an accuracy of \pm 0.02 (Holben et al., 1998), they can be treated as ground truth. Since AERONET AOD does not measure at wavelength $0.55 \mu \mathrm{m}$, we calculate it through log-linear interpolation from two nearest wavelengths, i.e. $0.5 \mu \mathrm{m}$ and $0.675 \mu \mathrm{m}$. We select six AERONET sites across continental US for the validation of MAIAC algorithm. Table 1 summarizes the locations of the AERONET sites used for the validation in this work and Fig. 1 shows their locations on the map of the United States.

\subsection{MODIS data}

MODIS BRDF (Lucht et al., 2000) in the band $2.12 \mu \mathrm{m}$ is used as an aid for the retrieval of surface BRDF from GOES visible channel radiances. Here, BRDF is modeled by RossThick-LiSparse model (Roujean et al., 1992), which contains three parts, including isotropic, geometric and volumetric scattering reflectance, as shown in the following equation:

$\rho\left(\theta_{s}, \theta_{v}, \phi\right)=k_{\text {iso }}+k_{\text {geo }} f_{\text {geo }}\left(\theta_{s}, \theta_{v}, \phi\right)+k_{\mathrm{vol}} f_{\mathrm{vol}}\left(\theta_{s}, \theta_{v}, \phi\right)$

where $\rho\left(\theta_{s}, \theta_{v}, \phi\right)$ is BRDF, $k_{\text {iso }}, k_{\text {geo }}$, and $k_{\mathrm{vol}}$ are the weights for the three components and $f_{\text {geo }}$ and $f_{\text {vol }}$ are kernel functions for geometric and volumetric components, respectively. The three BRDF weight parameters $\left(k_{\mathrm{iso}}, k_{\mathrm{geo}}, k_{\mathrm{vol}}\right)$ in the $2.1 \mu \mathrm{m}$ band are obtained from the MODIS level 2 land products MCD43D19, MCD43D20, and MCD43D21 with a spatial resolution of $1 \mathrm{~km}$. These BRDF parameters are derived from 16 days of MODIS surface reflectance (Vermote and Kotchenova, 2008) and are updated every eight days. MODIS surface reflectance has an uncertainty of $0.005+0.05 \rho$ (Vermote and Kotchenova, 2008). Therefore, the surface BRDF uncertainty is of similar magnitude.

MODIS level 2 aerosol optical depth product from Terra and Aqua is used for comparisons with the AOD retrievals from GOES. The MODIS aerosol retrieval algorithm over land uses three bands, i.e. blue band, red band, and SWIR band $(2.12 \mu \mathrm{m})$, to derive the aerosol properties with a $10 \mathrm{~km}$ spatial resolution at nadir (Levy et al., 2007).

\section{Aerosol optical depth retrieval algorithm}

One of the challenges in the satellite aerosol optical depth retrieval is the separation of the contributions from surface and from aerosol to the radiances at top of the atmosphere 
Table 1. Geographical locations of the AERONET sites.

\begin{tabular}{l|rr}
\hline Site name & Latitude & Longitude \\
\hline GSFC & $38.992^{\circ} \mathrm{N}$ & $76.84^{\circ} \mathrm{W}$ \\
Howland & $45.2^{\circ} \mathrm{N}$ & $68.733^{\circ} \mathrm{W}$ \\
Bondville & $40.053^{\circ} \mathrm{N}$ & $88.372^{\circ} \mathrm{W}$ \\
Railroad valley & $38.504^{\circ} \mathrm{N}$ & $115.962^{\circ} \mathrm{W}$ \\
Walker Branch & $35.958^{\circ} \mathrm{N}$ & $84.287^{\circ} \mathrm{W}$ \\
UCSB & $34.415^{\circ} \mathrm{N}$ & $119.845^{\circ} \mathrm{W}$ \\
\hline
\end{tabular}

(TOA). As mentioned previously, the retrieval of surface reflectance in GASP makes use of 28-day composite images at a specific observation time with an assumption that the surface reflectance does not change. However, due to the change of the Sun-satellite geometry and the change of surface vegetation during these 28 days, the surface reflectance may vary a lot, which may create large uncertainties in the AOD retrieval. For example, we observed a change from 0.11 to 0.14 in a 28 -day period at 16:45 UTC at GSFC site in the fall, which is obtained from the atmoshperic corrections of GOES visible data with the aid of AERONET AOD. An underestimate of surface reflectance of 0.03 can produce an AOD overestimate as large as 0.6. In Table 2, we show the surface reflectance change caused by the change in vegetation change. MODIS BRDF in the red band and green band are used to calculate the surface reflectance at GOES geometry in the $200 \times 200 \mathrm{~km}^{2}$ area centered at GSFC for the period between day 7 October and 8 November 2008. To focus only on the effect of the change in vegetation change, the geometry is fixed at 18:00 UTC on the 7 October 2008. We can see that the red band surface reflectance increases from 0.072 to 0.092 in the 24-day period from day 7 October to 31 October, and the green band surface reflectance increases from 0.080 to 0.088 in this period. Since GOES visible channel covers these two bands, we expect the surface reflectance change in GOES visible channel have the similar change in magnitude during the fall, which is about $10 \%$ to $27 \%$. Therefore, if we can reduce the number of days involved in the surface reflectance retrieval and use a more realistic BRDF model for surface reflectance retrieval, the uncertainties due to the surface reflectance retrieval can be reduced. Surface reflectance obtained from GASP algorithm are also affected by cloud shadows and the assumption of 0.02 background AOD in the second clearest day of the 28-day time sequence for surface reflectance retrieval.

The algorithm in this work applies the MAIAC algorithm designed for MODIS to the retrieval of AOD from GOES imager data. The algorithm makes following three assumptions: (1) BRDF in the GOES visible band is proportional to BRDF in the MODIS $2.12 \mu \mathrm{m}$ band, i.e. the BRDF shapes are the same in these two bands; (2) the BRDF shape does not change much within a season so that we can use a seasonal average of $2.12 \mu \mathrm{m}$ band BRDF from MODIS to represent
BRDF shape for each season; (3) since the mesoscale range of the aerosols is about 50-60 km (Anderson et al., 2003), aerosol is assumed to distribute uniformly over a distance of $24 \mathrm{~km}$. We assume AOD to be constant in each $24 \times 24 \mathrm{~km}^{2}$ block when we do time series analysis for surface BRDF retrieval.

Before applying the AOD retrieval algorithm, we perform an image co-registration for the images from GOES imager, since we found that the GOES images shift from time to time due to the jitter of the satellite orbit and a relatively low image navigation accuracy $(4 \mathrm{~km}$ at nadir, GOES I-M databook (1996)). To do this, we generate a reference image by projecting the MODIS average surface reflectance image onto the GOES channel 1 grid. All the input GOES images are compared against this reference image to correct the shifts. We select more than one hundred control points along the coastlines in such a way that the areas around the control points have high contrast and contain features that are suitable for pattern matching using a correlation method. For example, island and area with complex coastlines are good places for setting up the control points. The input GOES channel 1 images are compared against the reference image at each control point. A small window is selected around the control point to be used to determine the image shift there. We set the window size as $40 \times 40$. The GOES image from the small window is shifted iteratively and the correlation coefficient with the reference image at each shift position is calculated. If the GOES image within the small window is free from cloud, a correlation peak can be found when the small window area is colocated with the reference image. Therefore, the satellite image shift at the control point is determined to be the value at which the maximum correlation is found. If the GOES image within the window is covered by cloud, we are not able to find a large correlation with the reference. Thus, we require the maximum correlation be larger than 0.7 to be an effective shift calculation. To determine the shift over the whole image, we assume the shifts vary linearly with respect to the location:

$\Delta x(i, j)=A i+B j+C$,
$\Delta y(i, j)=D i+E j+F$,

where $\Delta x(i, j)$ and $\Delta y(i, j)$ is the shifts in $\mathrm{x}$ and $\mathrm{y}$ direction at pixel with index $(\mathrm{i}, \mathrm{j}), A, B, C, D, E, F$ are coefficients to be determined. Since the value of $\Delta x(i, j)$ and $\Delta y(i, j)$ at the control points free from clouds have already been determined above, we can calculate these coefficients through linear regression.

After image co-registration, the MAIAC retrieval algorithm for surface BRDF and AOD is applied. The algorithm flowchart is shown in Fig. 2. The GOES channel 1, 2, and 4 images are placed in a queue sorted by the time of acquisition for processing. We use the CLAVR algorithm for cloud mask, which is the same as the one used in GASP retrieval scheme. Since the spatial resolutions of two IR channels are 
Table 2. Surface reflectance change in red and green bands from MODIS BRDF due to the vegetation change. Surface reflectance statistics (mean \pm standard deviation) is calculated in the area (land surface only) centered at GSFC with $200 \times 200 \mathrm{~km}^{2}$ using MODIS BRDF in red and green bands. The geometry is fixed in GOES East geometry at 18:00 UTC on 7 October 2008, in order to remove the effect of the geometry change.

\begin{tabular}{l|ccccc}
\hline day & 7 October & 15 October & 23 October & 31 October & 8 November \\
\hline red & $0.072 \pm 0.022$ & $0.077 \pm 0.022$ & $0.088 \pm 0.023$ & $0.092 \pm 0.025$ & $0.090 \pm 0.025$ \\
green & $0.080 \pm 0.017$ & $0.081 \pm 0.016$ & $0.088 \pm 0.017$ & $0.088 \pm 0.019$ & $0.083 \pm 0.021$ \\
\hline
\end{tabular}

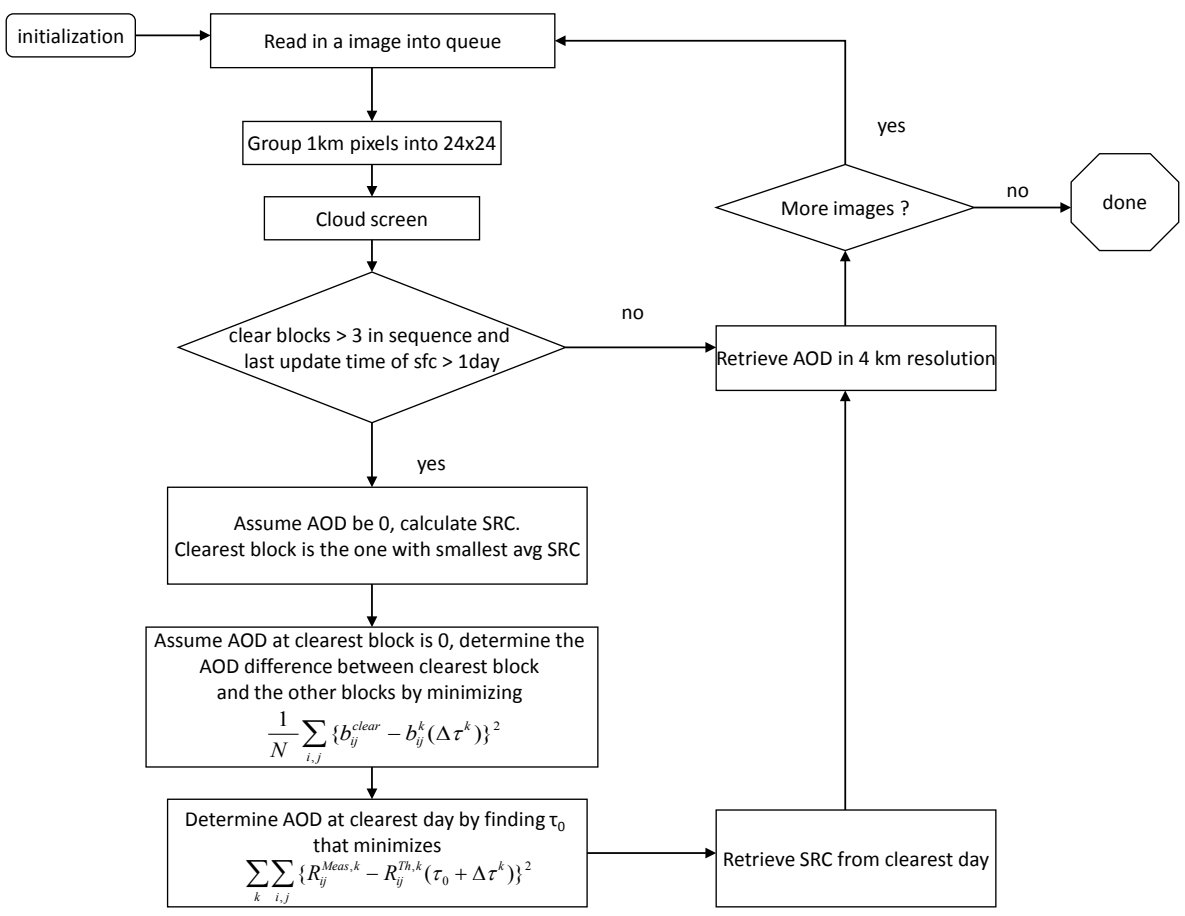

Fig. 2. Flowchart of the MAIAC algorithm for GOES AOD retrieval.

$4 \mathrm{~km}$, we break each pixel into $4 \times 4$ pixels with $1 \mathrm{~km}$ in size and assign each of the new pixels with the same value as the original one. With such arrangement, CLAVR algorithm can be applied at $1 \mathrm{~km}$ spatial resolution. Such arrangement is just a convenience to facilitate processing and it does not increase the information content of the GOES data. In addition, we also apply the following criterion to determine cloud pixels that fail to be masked in CLAVR algorithm: if the standard deviation of a $3 \times 3$ box surrounding a pixel in channel 1 TOA reflectance is greater than 0.015 , the pixel is also marked as cloudy, which is similar to the MODIS cloud mask algorithm by Martins et al. (2002). Because of the texture of the land surface, some boundaries with high contrast are misclassified as cloud. However, it is good to remove those boundaries in surface and aerosol retrievals since they are most likely to reduce retrieval accuracy due to the relatively high residue error in image co-registration.

After cloud masking, the $1 \mathrm{~km}$ spatial resolution grids are grouped into blocks with size $24 \times 24$. Surface BRDF at each pixel is derived through retrieving the spectral regression coefficients (SRC) between MODIS $2.12 \mu \mathrm{m}$ BRDF and GOES channel 1 BRDF. Here, SRC is defined as the ratio between GOES channel 1 band BRDF and MODIS $2.12 \mu \mathrm{m}$ band BRDF. We perform SRC retrieval if there are at least three cloud free blocks in the time sequence. The time sequence of a block contains the GOES images of the same area measured at different time. We set the size of the time sequence to be 20, which contains about one day of GOES data. For each pixel within a block, we calculate the SRC with the assumption that AOD is 0 . A block is considered to be clearest (with lowest AOD) if its average SRC is the lowest in the time sequence. Next, the AOD difference between each block and the clearest block is determined by looking for the AOD difference that minimizes the difference between SRCs from these two observations, i.e. the AOD difference is $\Delta \tau^{k}$ that minimizes $\frac{1}{N} \sum_{i, j}\left\{b_{i j}^{\text {clearest }}-b_{i j}^{k}\left(\Delta \tau^{k}\right)\right\}^{2}$, where $N$ is the number of pixels that are cloud free in both the clearest image block and the image block for comparison 
$(k), b_{i j}^{\text {clearest }}$ is SRC at the clearest time for pixel with indices $i$ and $j, b_{i j}^{k}\left(\Delta \tau^{k}\right)$ is the SRC at observation $k$ for pixel with indices $i$ and $j$ if the AOD difference between image block $k$ and the clearest image block is $\Delta \tau^{k}$.

Next, we calculate AOD at the clearest observation, which is obtained by looking for the AOD value that minimizes the root mean square differences between the theoretical TOA radiance and the measured TOA radiance for all the blocks in the queue, i.e. looking for $\tau_{0}$ that minimizes the quantity $\sum_{k} \sum_{i, j}\left\{R^{\text {Meas }}, k_{i j}-R_{i j}^{T h, k}\left(\tau_{0}+\Delta \tau^{k}\right)^{2}\right.$, where $R_{i j}^{\text {Meas }, k}$ is the measured radiance at pixel $(i, j)$ for image block $k$, $R_{i j}^{T h, k}\left(\tau_{0}+\Delta \tau^{k}\right)$ is the theoretical radiance at this pixel for image block $k$ if AOD for the clearest image is $\tau_{0}$. AOD derived at this step is the average AOD over the whole block to help retrieve surface BRDF.

AOD at the clearest observation is then used to retrieve SRC and surface BRDF at each pixel within the block. To retrieve AOD at a higher spatial resolution, we regroup GOES channel 1 image into $4 \times 4$. If the total number of cloud free pixels in a group is greater than 8 , i.e. more than half of the pixels are cloud free, we retrieve AOD in this group using average TOA reflectance and average surface BRDF of the cloud free pixels.

The retrieval algorithm described above is implemented with the aid of a look-up-table (LUT). Unlike GASP, in which Lambertian $6 \mathrm{~S}$ radiative transfer model (Vermote et al., 1997) is used to generate LUT, we use non-Lambertian SHARM model (Lyapustin and Knyazikhin, 2001; Lyapustin and Wang, 2005). In this model, the reflectance at the top of the atmosphere $(\rho)$ can approximately be written as (Lyapustin and Wang, 2008):

$\rho=\rho^{D}(\tau)+b\left[k_{\text {iso }}^{B 7} F_{\text {iso }}(\tau)+k_{\text {geo }}^{B 7} F_{\text {geo }}(\tau)+k_{\mathrm{vol}}^{B 7} F_{\text {vol }}(\tau)\right]$,

where $\rho^{D}$ represents the atmospheric path reflectance, $b$ is the SRC between GOES channel 1 and MODIS $2.1 \mu \mathrm{m}$ band BRDF, $k_{\text {iso }}^{B 7}, k_{\mathrm{geo}}^{B 7}, k_{\mathrm{vol}}^{B 7}$ are weights of BRDF in the MODIS $2.1 \mu \mathrm{m}$ band, $F_{\text {iso }}, F_{\text {geo }}, F_{\text {vol }}$ are reflectance contribution from isotropic, geometric and volumetric part of surface BRDF, respectively. The detailed expressions of $F_{\text {iso }}$, $F_{\mathrm{geo}}, F_{\mathrm{vol}}$ can be found in Lyapustin and Wang (2008). In LUT, we save $\rho^{D}$ and functions to calculate $F_{\text {iso }}, F_{\text {geo }}, F_{\text {vol }}$ for different sun-satellite geometry and AOD combinations.

We use an aerosol model with fine and coarse fractions in lognormal distribution with following parameters: $R_{v}=0.14 \mu \mathrm{m}, 3.2 \mu \mathrm{m}, \sigma_{v}=0.35 \mu \mathrm{m}, 0.7 \mu \mathrm{m}, n_{r}=1.45, n_{i}=$ 0.006 . The ratio of volumetric concentrations between the coarse and fine mode is $C v_{\text {coarse }} / C v_{\text {fine }}=0.5$. This model is similar to the aerosol model from AERONET at GSFC. We use climatological values of column ozone and water vapor for gaseous absorption calculation since their variations do not introduce much variation on the surface reflectance and AOD retrievals (Knapp et al., 2002; Zhang et al., 2008).

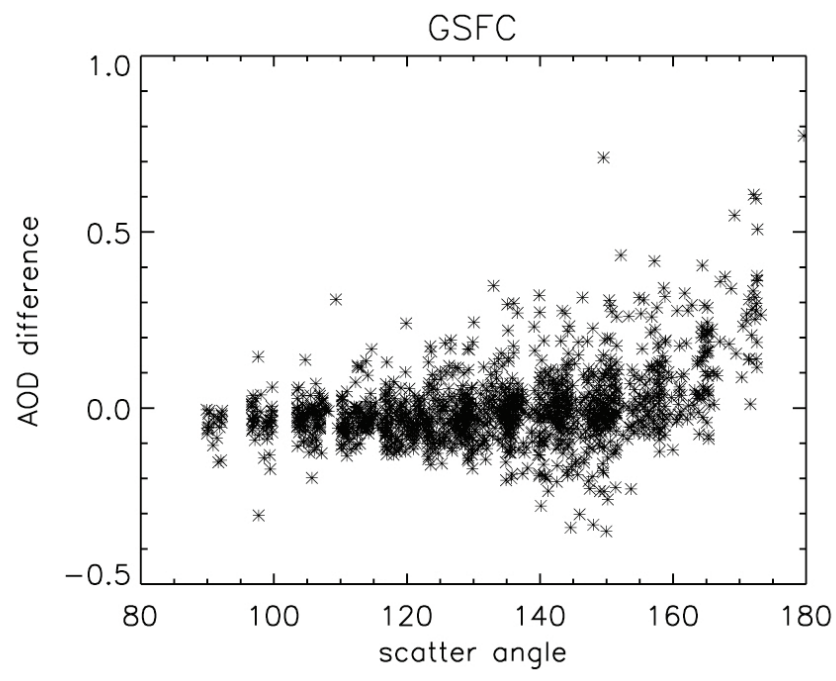

Fig. 3. AOD error vs scatter angle at GSFC site, where AOD error is defined as GOES AOD minus AERONET AOD.

\section{Results and validation}

\subsection{Comparison of AOD retrieval against AERONET and GASP}

The AOD retrieval results are compared to the AERONET measurements at the six AERONET sites over the United States described in Sect. 2.2. To find the coincidence between GOES AOD retrieval and AERONET measurements, we use the average GOES AOD retrievals within $5 \times 5$ box surrounding the AERONET site and the interpolation of two closest AERONET measurements within 15 minutes before and after GOES observation. In cases where only one AERONET measurement is available within \pm 15 min time frame, we use that value instead of interpolation. To further remove cloud contamination, we remove the pixels adjacent to cloud, require more than 10 effective pixels in the 25 pixels, and require standard deviation of AOD in the $5 \times 5$ box is less than 0.2. We also use two additional filters for backscatter geometry and bright surface, which are described in the following two subsections. GASP data are prepared using average in $5 \times 5$ box surrounding the AERONET site and are applied the filters described in Prados et al. (2007). In addition, GASP data also uses a standard deviation threshold of 0.2 for cloud contamination removal. Because of the difference in the retrieval and screening algorithm, the coincidences of AOD retrievals are not exactly the same between MAIAC and GASP. The dataset covers the period between 1 March 2008 and 25 September 2008. 

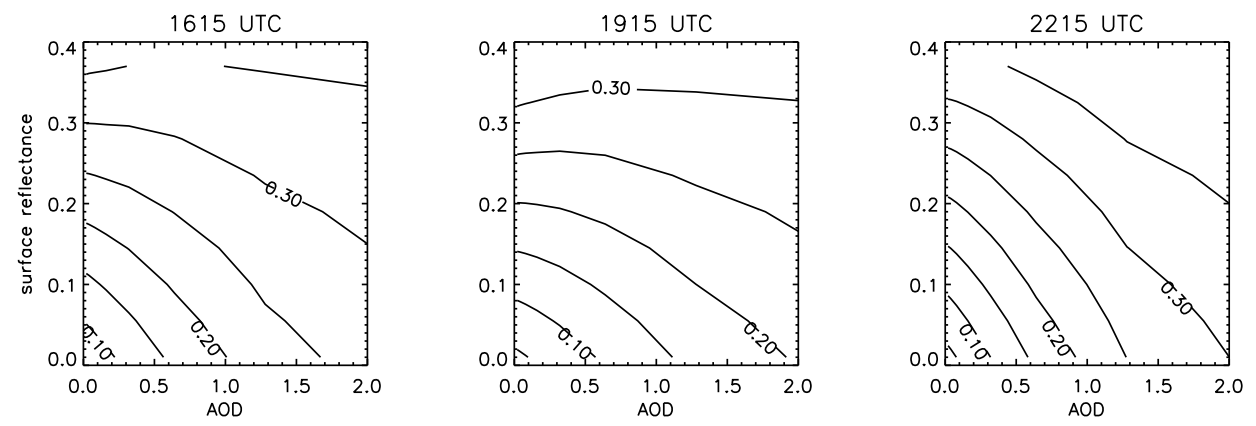

Fig. 4. Contour of TOA reflectance vs surface reflectance and AOD at Railroad Valley site.

\subsubsection{Backscatter geometry}

At backscatter geometry where the Sun is located directly at the back of the satellite, we notice large bias in the AOD retrievals. Figure 3 shows the AOD retrieval errors vs scatter angle at GSFC site. We can see that the errors increase systematically when scatter angle increases above $160^{\circ}$. The backscatter geometry corresponds to the location of hot spot where surface BRDF is the highest. Such errors are caused by the large errors of MODIS BRDF close to the hot spot. MODIS BRDF retrievals do not model the hot spot well if MODIS do not sample at the positions close to the hot spot at backscatter geometry. We can also see that the errors are relative small at scatter angles below $160^{\circ}$, which indicate that MODIS BRDF works well away from hot spot. In the following validation, we remove the AOD retrievals with scatter angle larger than $160^{\circ}$. In GASP, most retrievals at such geometries are also removed due to high surface reflectance since GASP filters out pixels with surface reflectance larger than 0.15 .

\subsubsection{Bright surface}

In this work, we use a different filter for bright surfaces, mostly located in the western US. Railroad Valley site at Nevada is very bright and it is a good site to test the GOES AOD retrieval algorithm at locations with high surface reflectance. The Sun-satellite geometries at Railroad Valley can also represent typical geometries of western US. Figure 4 shows contours of TOA reflectance as a function of surface reflectance and AOD at three geometry setups at Railroad Valley site: morning (16:15 UTC), noon (19:15 UTC), and afternoon (22:15 UTC). We can see that the 0.2 contour line at noon with surface reflectance close to 0.2 and AOD close to 0 is almost flat, which indicates that a small surface reflectance error can introduce a large AOD error. Hence AOD uncertainty is high at such geometry and surface reflectance combination. We can also see that at high surface reflectance at some Sun-satellite geometries the TOA reflectance decreases even if AOD increases. In such geometries, we get two solutions of AOD with given TOA reflectance and sur- face reflectance. Such phenomenon was also observed in previous research by Fraser and Kaufman (1985); Kaufman (1987). In the afternoon, the contours are mostly falling downward as AOD increases and, therefore, the AOD retrieval error should be much less sensitive to errors in surface reflectance. From such observation, the sensitivity of AOD retrieval over surface reflectance is dependent on both the Sun-satellite geometry and the value of surface reflectance. It is not appropriate to use a uniform threshold of surface reflectance to filter out AOD retrievals with high sensitivity to surface reflectance retrieval.

Based on the above discussion, instead of using fixed surface reflectance threshold, we apply a new filter to remove noisy AOD retrievals due to the errors in surface reflectance. This filter uses $\left.\frac{\partial \tau}{\partial \rho_{\mathrm{sfc}}}\right|_{\tau=0}$, with TOA reflectance and Sunsatellite geometry fixed, to remove inaccurate retrievals due to the surface reflectance retrieval errors. The AOD retrievals are removed if this value is smaller than -20 and larger than 0 . Since we can write AOD retrieval error as $\Delta \tau=\frac{\partial \tau}{\partial \rho_{\mathrm{sfc}}} \Delta \rho_{\mathrm{sfc}}$, if other conditions are not changed, large $\left|\frac{\partial \tau}{\partial \rho_{\mathrm{sfc}}}\right|$ value means that large AOD error can be introduced with error in surface reflectance retrieval. If $\frac{\partial \tau}{\partial \rho_{\text {sfc }}}$ is positive at $0 \mathrm{AOD}$, it is possible that the value turns negative at some higher AOD value, which suggests two AOD solutions for the same set of parameters, i.e. $\rho_{\mathrm{sfc}}, \rho_{\mathrm{TOA}}$, and three geometric angles.

\subsubsection{Validation of AOD retrievals}

Figure 5 shows the scatter plots of MAIAC vs AERONET AOD at the six AERONET sites. For comparison, Fig. 6 shows the corresponding scatter plots of GASP vs AERONET AOD. MAIAC retrievals have correlation of more than 0.8 at GSFC, Railroad Valley, and UCSB site. MAIAC retrievals have smaller RMSE than GASP retrievals at all the sites. Because the two retrieval algorithms use different screening scheme to remove noisy data, the numbers of AOD retrievals are different in the two retrieval algorithms. Table 3 shows the linear regression results for MAIAC AOD vs. AERONET AOD and GASP AOD vs AERONET AOD with one-to-one correspondence between 
Table 3. Comparisons between MAIAC vs. AERONET and GASP vs. AERONET with one-to-one correspondence between MAIAC and GASP AOD.

\begin{tabular}{l|c|cccr|crrr}
\hline & \multicolumn{7}{|c|}{ MAIAC } & \multicolumn{5}{c}{ GASP } \\
\hline & $N$ & $R$ & RMSE & slope & intercept & $R$ & RMSE & slope & intercept \\
\hline GSFC & 749 & 0.82 & 0.08 & 0.84 & 0.00 & 0.81 & 0.10 & 1.12 & -0.01 \\
Walker Branch & 537 & 0.73 & 0.09 & 0.70 & 0.05 & 0.74 & 0.10 & 0.86 & 0.00 \\
Howland & 298 & 0.67 & 0.07 & 0.65 & 0.00 & 0.66 & 0.08 & 0.79 & 0.00 \\
Bondville & 510 & 0.43 & 0.14 & 0.66 & 0.07 & 0.42 & 0.20 & 0.89 & 0.08 \\
Railroad Valley & 155 & 0.83 & 0.04 & 0.84 & -0.01 & 0.69 & 0.14 & 1.28 & 0.10 \\
UCSB & 132 & 0.86 & 0.04 & 1.07 & -0.03 & 0.67 & 0.08 & 1.11 & 0.03 \\
\hline
\end{tabular}
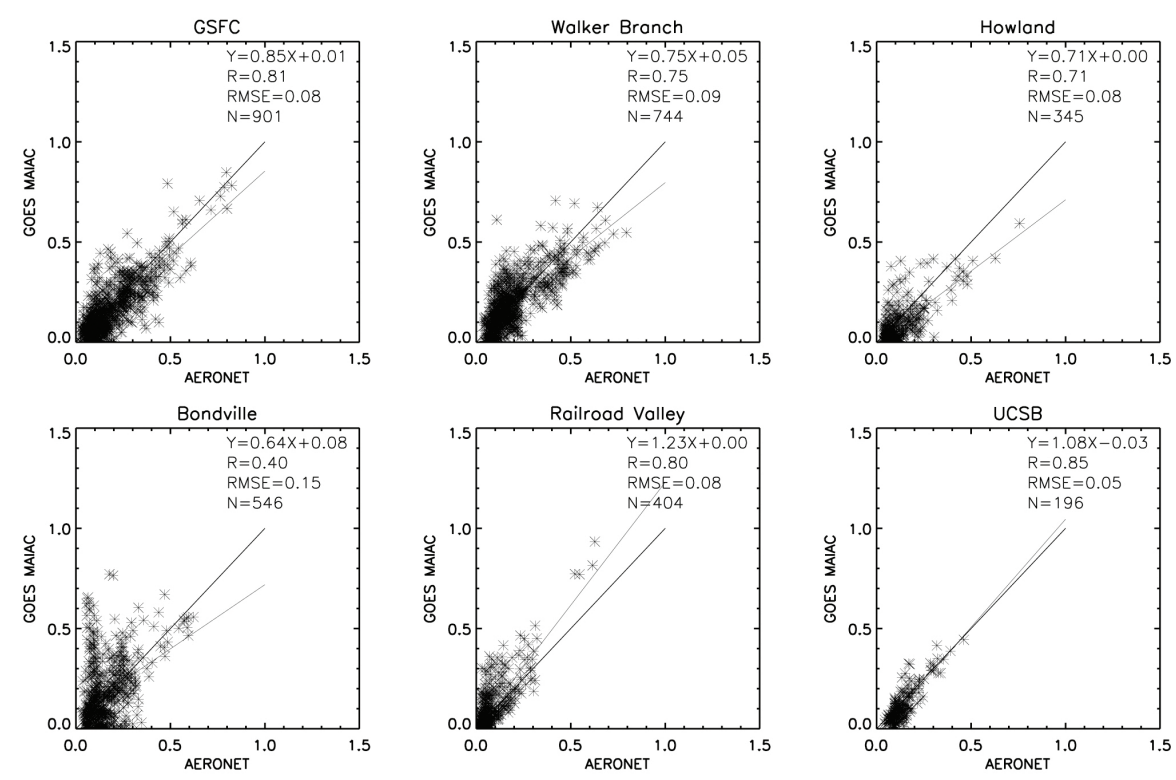

Fig. 5. Scatter plot of MAIAC vs. AERONET AOD.

MAIAC and GASP retrievals. With one-to-one correspondence, MAIAC retrievals have similar correlation with AERONET AOD to the GASP retrievals vs AERONET AOD at eastern and central sites, i.e. GSFC, Walker Branch, Howland, and Bondville, but MAIAC have smaller RMSE at three of them: GSFC, Walker Branch, and Bondville. At the two western sites, MAIAC AOD retrievals are much more accurate than GASP retrievals in both correlation coefficient and RMSE.

There are several reasons that may increase or decrease the accuracy in the MAIAC algorithm in comparison to GASP. First, MAIAC algorithm requires less number of days to retrieve surface BRDF: normally surface BRDF can be retrieved in one day if three clear observations are found. This can reduce uncertainties in surface BRDF retrieval due to the change in surface BRDF during a period shorter than 28 days, which is used in GASP for surface retrieval. The GASP method tends to pick up cloud shadow in some geometries, e.g. during the afternoon in the western US when the sun shines from the west. Second, in MAIAC, we use a more realistic aerosol model which is similar to that retrieved from GSFC. GASP uses a different aerosol model, i.e. continental model, which has a lower single single scatter albedo, and hence GASP tends to have higher AOD retrievals than MAIAC. Third, we use a new screen algorithm at bright surface described in the last section. This screen scheme generates a larger number of retrievals at bright surface than the use of simple threshold of 0.15 surface reflectance. We can see that at Railroad Valley there are more coincidences available in MAIAC than those in GASP.

The difference between seasonally averaged BRDF shape and BRDF shape of a particular day may also introduce AOD retrieval error. MODIS BRDF retrieval error is also a major source of uncertainty, which is extremely large at backscattering position. The retrieval algorithm is based on an assumption that surface BRDF is relative stable from day to day. If the surface BRDF is unstable, large AOD error may occur. This is especially serious at Bondville, where 

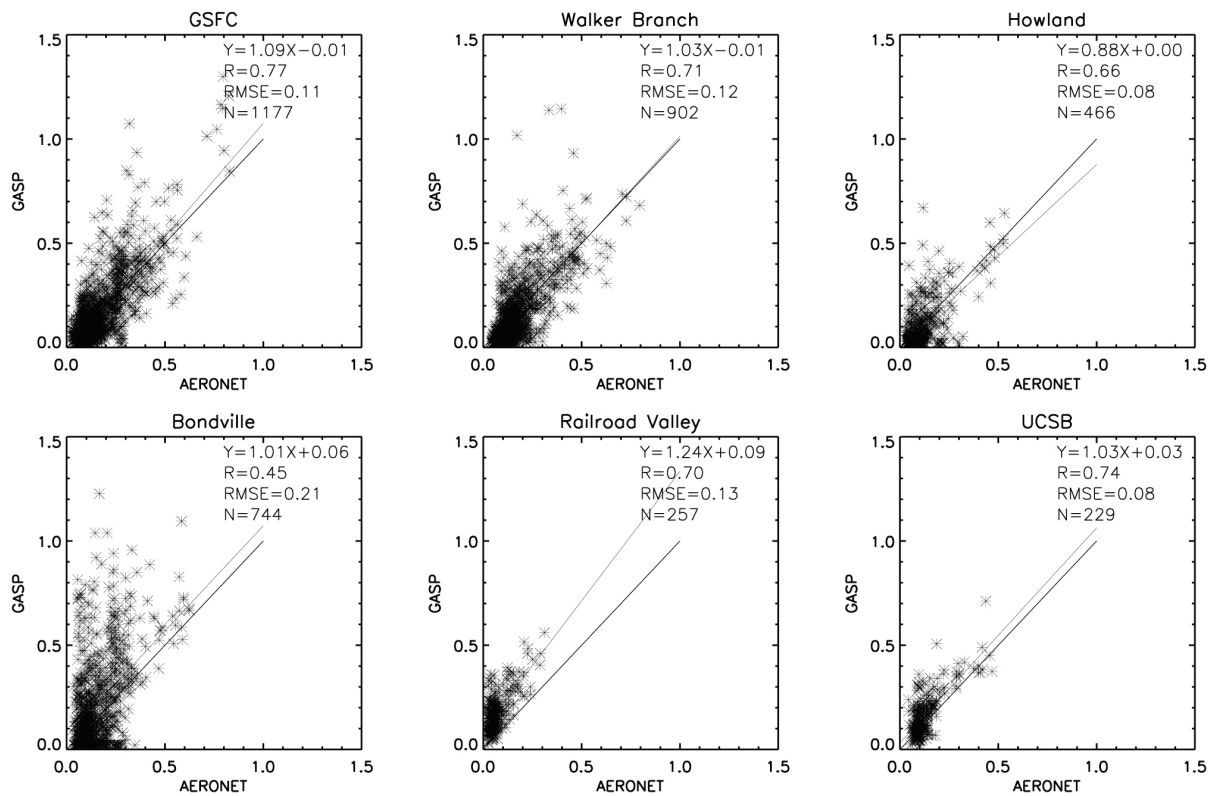

Fig. 6. Scatter plot of GASP vs. AERONET AOD.
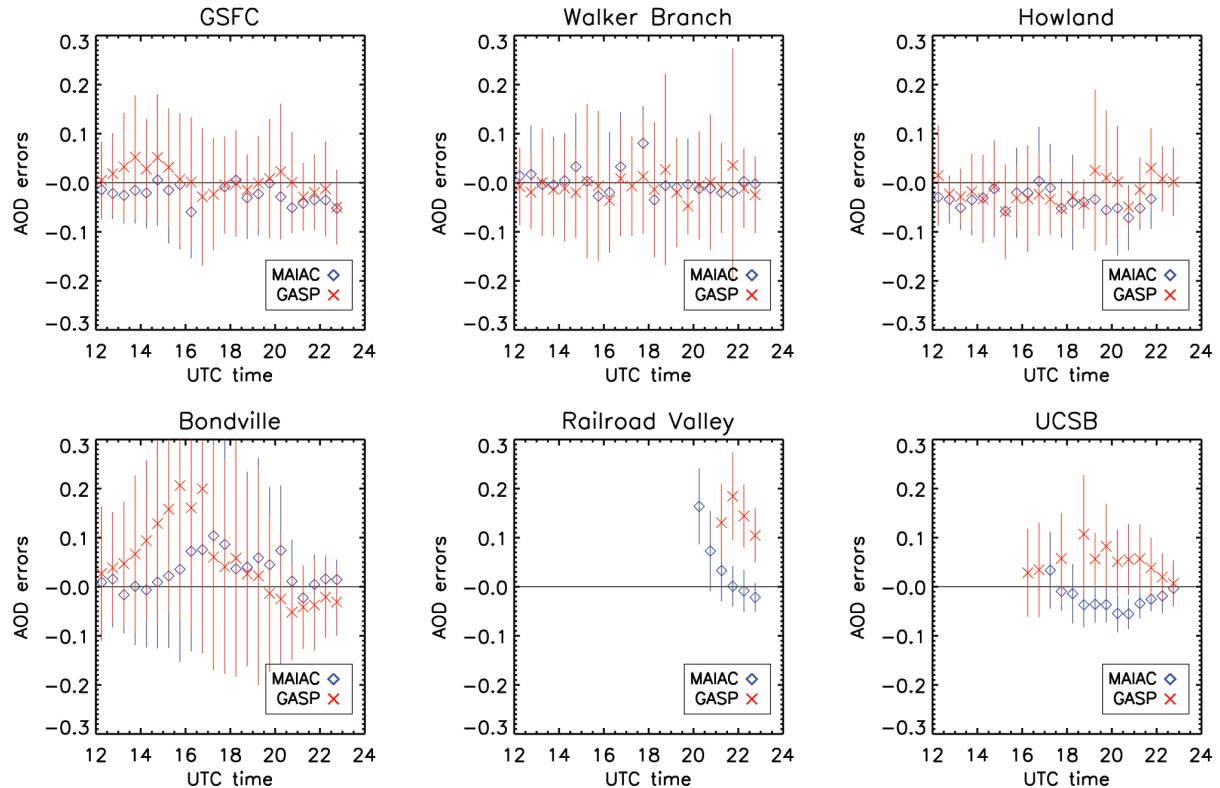

Fig. 7. AOD retrieval errors vs. UTC time. AOD retrieval error is defined as GOES AOD minus AERONET AOD.

both MAIAC and GASP have large retrieval errors compared to AERONET. We found that at Bondville site the surface BRDF changes rapidly during the period between March and June, when there is no vegetation there. During that period, there are raining days from time to time and the surface changes between wet and dry from day to day, which introduces instability of surface reflectance. Since the western US has much less precipitation, BRDF has less variation from time to time. This is one of the reason that AOD re- trievals are more accurate at the two western sites than those at the eastern sites.

Figure 7 shows the diurnal variations of the average errors of AOD retrievals with standard deviation as error bar. The patterns vary from site to site. We don't observe any apparent pattern at the three eastern sites. However, at the other three sites, i.e. Bondville, Railroad Valley, and UCSB, we find that the errors are larger at noon than in the morning and in the afternoon. 

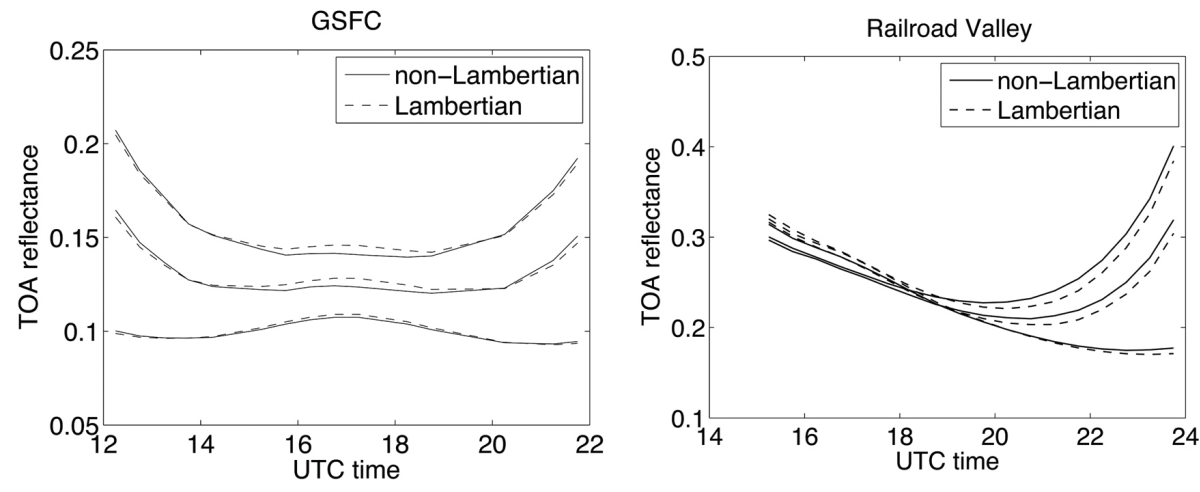

Fig. 8. Comparison of TOA reflectance between Lambertian and non-Lambertian surface at site GSFC and Railroad Valley. The three pairs of lines from bottom to top are calculated using AOD values of $0,0.5$, and 1.0 , respectively.

\subsubsection{Non-Lambertian effect}

We use non-Lambertian SHARM radiative transfer model in our retrieval, which can introduce AOD retrieval difference from the retrievals using radiative transfer models that assumes Lambertian surface. To analyze the AOD retrieval difference between using non-Lambertian model and using Lambertian model, we calculate the diurnal variations of the TOA reflectance at GSFC and Railroad Valley using typical values of surface BRDF at these two sites, shown in Fig. 8. GSFC site is located in the eastern US in Maryland state and surface reflectance peaks at local noon due to the Sunsatellite geometry. Railroad Valley is located in the western US in Nevada and the surface reflectance is high in the morning and decreases during the day time. In both sites, we can see that the TOA reflectance is overestimated at high surface BRDF geometry and underestimated at low surface BRDF geometry. If Lambertian surface is assumed, AOD will be underestimated at noon at GSFC and in the morning at Railroad Valley and will be overestimated in the early morning and in the late afternoon at GSFC and in the afternoon at Railroad Valley. At GSFC site, the differences of TOA reflectance between the two surface assumptions are about 0.05 at AOD 0.5 and 1.0, and about 0.02 at AOD close to 0 at noon when the differences are large. Such differences can introduce underestimates of AOD 0.15 for AOD equal to 0.5 and 1.0 and introduce underestimate of AOD 0.05 if AOD is close to 0. At Railroad Valley, we don't have retrievals in the morning because of the high surface reflectance caused uncertainty discussed in the previous sections. The AOD retrievals are more sensitive to the surface assumption in the early afternoon than in the late afternoon. At 20:15 UTC, Lambertian assumption can cause $0.07,0.2$, and 0.25 error for AOD at 0, 0.5, and 1.0, respectively. At 22:15 UTC, Lambertian assumption can introduce $0.03,0.1$, and 0.18 error for $\mathrm{AOD}$ at $0,0.5$, and 1.0 , respectively. In both time instances, the AOD retrievals are overestimated if Lambertian surface is assumed. From the analysis above, we introduce an AOD re- trieval uncertainty as large as $15-20 \%$ in some Sun-satellite geometry if we use a Lambertian surface assumption. However, error of such magnitude is small compared to other error sources such as surface reflectance and cloud contamination. From the scatter plots shown above, the AOD retrieval error is about 0.2 for AOD close to 0 , which is much larger than the error from using Lambertian model. Therefore, the improvement through using the non-Lambertian radiative transfer model is small and do not show a big influence in the scatter plots comparisons between MAIAC and GASP.

\subsection{Evaluation of surface reflectance retrievals}

The benefit of MAIAC algorithm is the potential of improving the accuracy of the surface reflectance retrievals. This is achieved by reducing the number of days used in the time sequence for the surface reflectance retrieval, and also by abandoning the assumption of $\mathrm{AOD}=0.02$ in the second clearest day, which is used in GASP surface reflectance retrieval. The retrieval of surface reflectance over a block can usually be obtained by a sequence of cloud free images from the same day if more than three such images are found for this block. AOD at the clearest observation time is retrieved using time sequence analysis. However, two new assumptions are made in such retrievals: the BRDF shape of GOES channel 1 is proportional to that derived from MODIS $2.12 \mu \mathrm{m}$ channel, and the BRDF shape does not have large variation during a season. The accuracy of such assumptions and the accuracy of MODIS $2.12 \mu \mathrm{m}$ BRDF retrievals has direct effect on the accuracy of GOES surface reflectance retrievals and hence the accuracy of AOD retrievals.

To evaluate the accuracy of the surface reflectance, we use the GOES channel 1 TOA reflectance and AERONET AOD together with LUT to correct the atmosphere effect and obtain estimation of the surface reflectance at the AERONET sites. This method was also used previously by Hauser et al. (2005), Knapp et al. (2005), and Popp et al. (2007) and its 

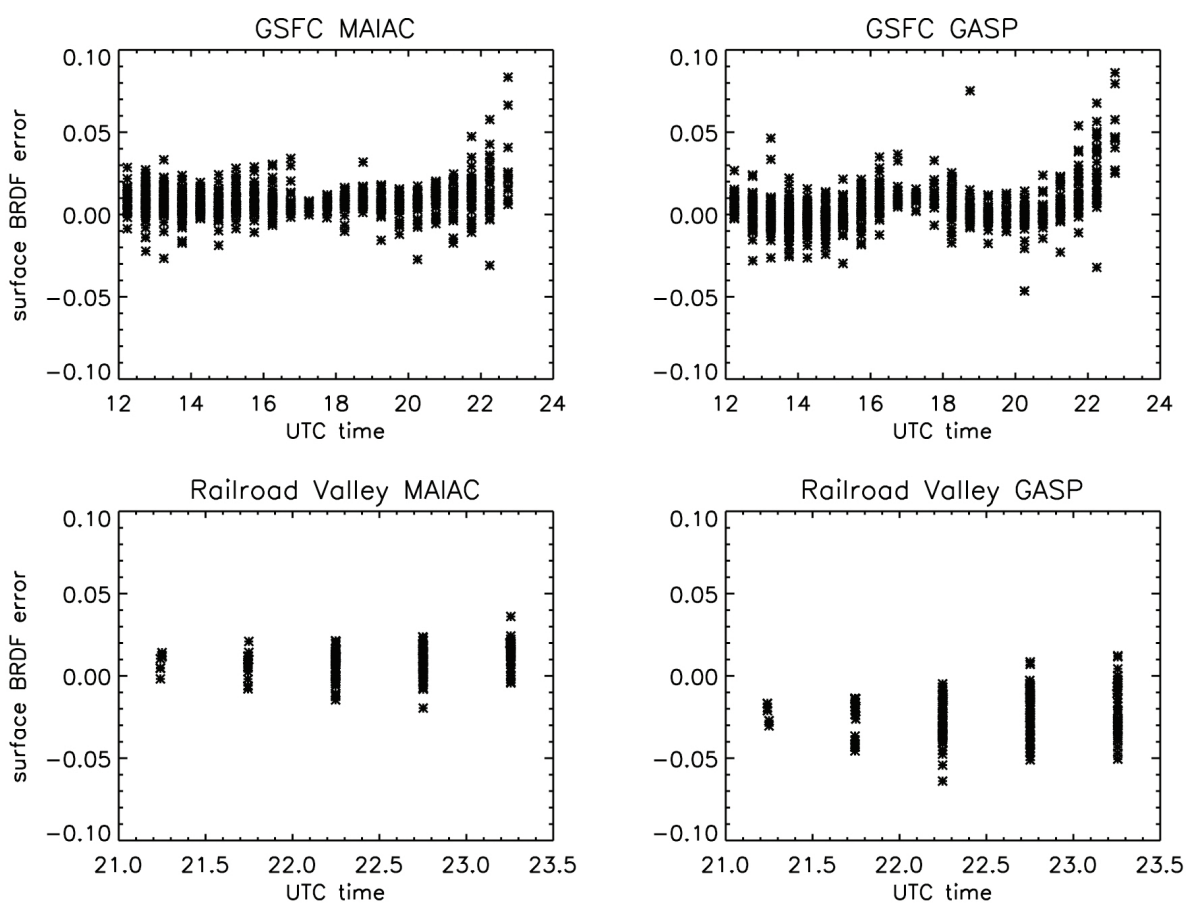

Fig. 9. Surface BRDF error at GSFC and Railroad Valley, which is defined as surface reflectance retrieval from MAIAC or GASP minus surface reflectance retrieval using GOES channel 1 data and AERONET AOD.

accuracy is affected by cloud and cloud shadow contamination.

Figure 9 shows the BRDF retrieval errors at two AERONET sites, i.e. GSFC and Railroad Valley, vs. UTC time. To compare MAIAC and GASP, the data shown have one-to-one correspondence between MAIAC and GASP. At GSFC site, both MAIAC and GASP appear to have similar error magnitudes and variations. At Railroad Valley, because surface reflectance is high and the TOA reflectance is not sensitive to AOD during the morning and noon, the retrievals are only available in the afternoon. MAIAC surface reflectance retrievals are more accurate than GASP surface reflectance retrievals at Railroad Valley site. We can notice that GASP tends to underestimate surface BRDF there. To understand the causes of the surface retrieval errors in GASP and the benefit of MAIAC algorithm, we plot in Fig. 10 time series of surface reflectance at GSFC (19:15 UTC) and Railroad Valley (22:15 UTC) in areas of $20 \times 20 \mathrm{~km}^{2}$. The surface reflectance is obtained using channel 1 GOES signal and AERONET AOD, as described in the previous paragraph. We can see that the surface reflectance is not a constant over time. The variation of surface reflectance is less at GSFC than at Railroad Valley. At GSFC, the surface reflectance has a down trend in the testing period. Since GASP retrieval picks second darkest in 28-day period, it tends to select the latest surface reflectance. Therefore, GASP algorithm does not have large bias. Although using MAIAC can reduce the time period for surface retrieval, such benefit does not show at GSFC site for the period of test. However, the situation is different at Railroad Valley site. We observe high frequency of variation in surface reflectance with large range. Using GASP, surface reflectance retrieved tends to be at the lower bound of the time series. Also, during day 100 to 200, the uptrend of the time series induces GASP to select the earliest surface reflectance within the 28-day period. Due to this reason, we observe underestimates of surface reflectance in GASP around 0.03. Since MAIAC retrieval does not select the dark pixels in the time series, it does not have such tendancy to retrieve lower bound of the surface reflectance and its retrievals are between the lower bound and the upper bound. In addition, MAIAC uses a short period of time for surface retrieval. It does not suffer from the long term tendancy of surface reflectance variation.

\subsection{Other sources of errors}

Besides surface reflectance, there are other sources of AOD retrieval errors, including calibration, cloud contamination, aerosol model, etc. GOES visible channel uses vicarious calibration methods (http://www.star.nesdis.noaa.gov/smcd/ spb/fwu/homepage/GOES_Imager_Vis_OpCal.php). The methods include star-based calibration, lunar-based calibration, deep convection cloud calibration, desert-based calibration, GOES-GOME inter-calibration, calibration using MODIS. The calibration methods estimate the degradation rate of GOES visible channel sensor. From the difference between the different calibration methods, we estimate that the 

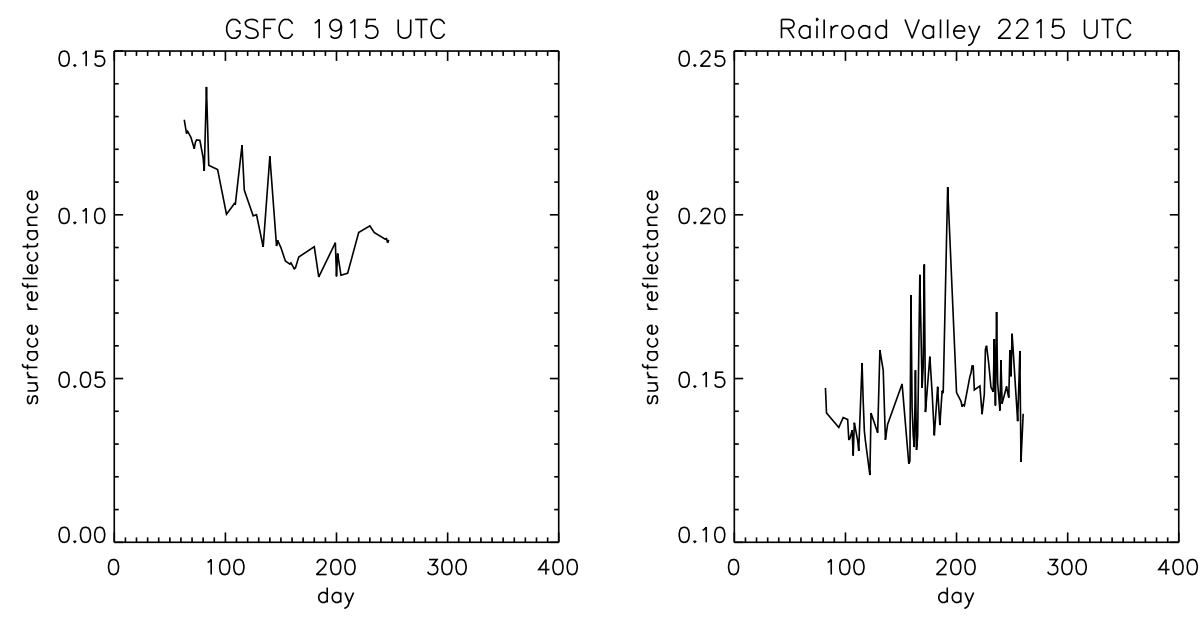

Fig. 10. Surface reflectance timeseries at GSFC (19:15 UTC) and Railroad Valley (22:15 UTC). The surface reflectance is retrieved using GOES channel 1 TOA reflectance and AERONET AOD in $20 \times 20 \mathrm{~km}^{2}$ areas at the AERONET sites.

calibration error is about $5 \%$. However, since surface BRDF is also derived from the same calibration, the error from the calibration tends to be lower since both surface BRDF and TOA reflectance are biased similarly.

Cloud contamination is another source of error. We have made efforts to improve cloud masks, such as applying threshold for standard deviation in $3 \times 3$ pixels box. However, we still cannot eliminate the subpixel scale cloud and thin cirus cloud, which can generate overestimated AOD.

Because we only have one visible channel to be used for aerosol retrieval, we do not have the degree of freedom to select aerosol models and therefore we use a single aerosol model in the retrieval. In reality, aerosol model can change and thus cause AOD retrieval error. To estimate such error, we calculated TOA reflectance using biomass burning model and dust model at different geometries and compare against the one used in MAIAC. We find that the error from using wrong aerosol model can be as high as $25 \%$.

When AOD is small, the AOD retrieval error originating from calibration and aerosol model is also small, i.e. the error approaches 0 if AOD is close to 0. Both GASP and MAIAC uses similar cloud mask schemes, the difference between them at small AOD is therefore mainly originated from the differences in their surface reflectance retrievals. The difference is apparent at the two western sites as seen in Table 3. For example, at Railroad Valley, the intercept is 0.1 for GASP vs. AERONET AOD, and it is -0.01 for MAIAC vs. AERONET AOD. At the four other sites in the eastern and central US, the differences are small.

\subsection{A regional retrieval example}

In this section, we demonstrate a regional retrieval example using the MAIAC algorithm for a California fire case in July 2008. Figure 11 shows an example of California fire AOD retrievals from MAIAC, GASP, Terra and Aqua on 10
July 2008. MAIAC AOD retrievals demonstrate much better quality than those from GASP and MODIS. The AOD data coverage from MAIAC is larger than GASP because MAIAC uses a different screen algorithm for high reflectance surface, which is described in the previous section. Because of high surface reflectance over this area and MODIS uses dark pixels for AOD retrieval, MODIS AOD maps also show large areas without retrieval. MAIAC AOD map shows more detailed smoke plume structures than MODIS AOD map because of the higher spatial resolution. MAIAC AOD retrievals are also sensitive to surface reflectance and they have larger errors when surface reflectance is high. In the western US, the surface reflectance is high in the morning and low in the afternoon if the area is viewed from the GOES-12 satellite position. Hence the accuracy of the AOD retrievals for the western US is high in the afternoon for GOES-12.

Figure 12 shows the scatter plot of the AOD retrievals from MAIAC vs those from MODIS Aqua. GASP AOD vs. MODIS Aqua AOD scatter plot is also shown for comparison. GOES AOD used here was taken from the retrievals at 20:15 UTC, which is closest to the overpass time of Aqua. MAIAC AOD has a good correlation of 0.87 with MODIS Aqua and it is better than that between GASP AOD and MODIS AOD. MAIAC AOD shows lower retrieval values than MODIS AOD with a slope of 0.56. This is reasonable since MODIS AOD was found to overestimate in the southwest region of US (Drury et al., 2008).

\section{Conclusions}

We develop a new AOD retrieval algorithm by modifying the MAIAC algorithm for MODIS. In this algorithm, seasonally averaged MODIS surface BRDF in the $2.1 \mu \mathrm{m}$ band is used along with the GOES visible channel for the retrieval of surface reflectance and AOD. This algorithm can retrieve 

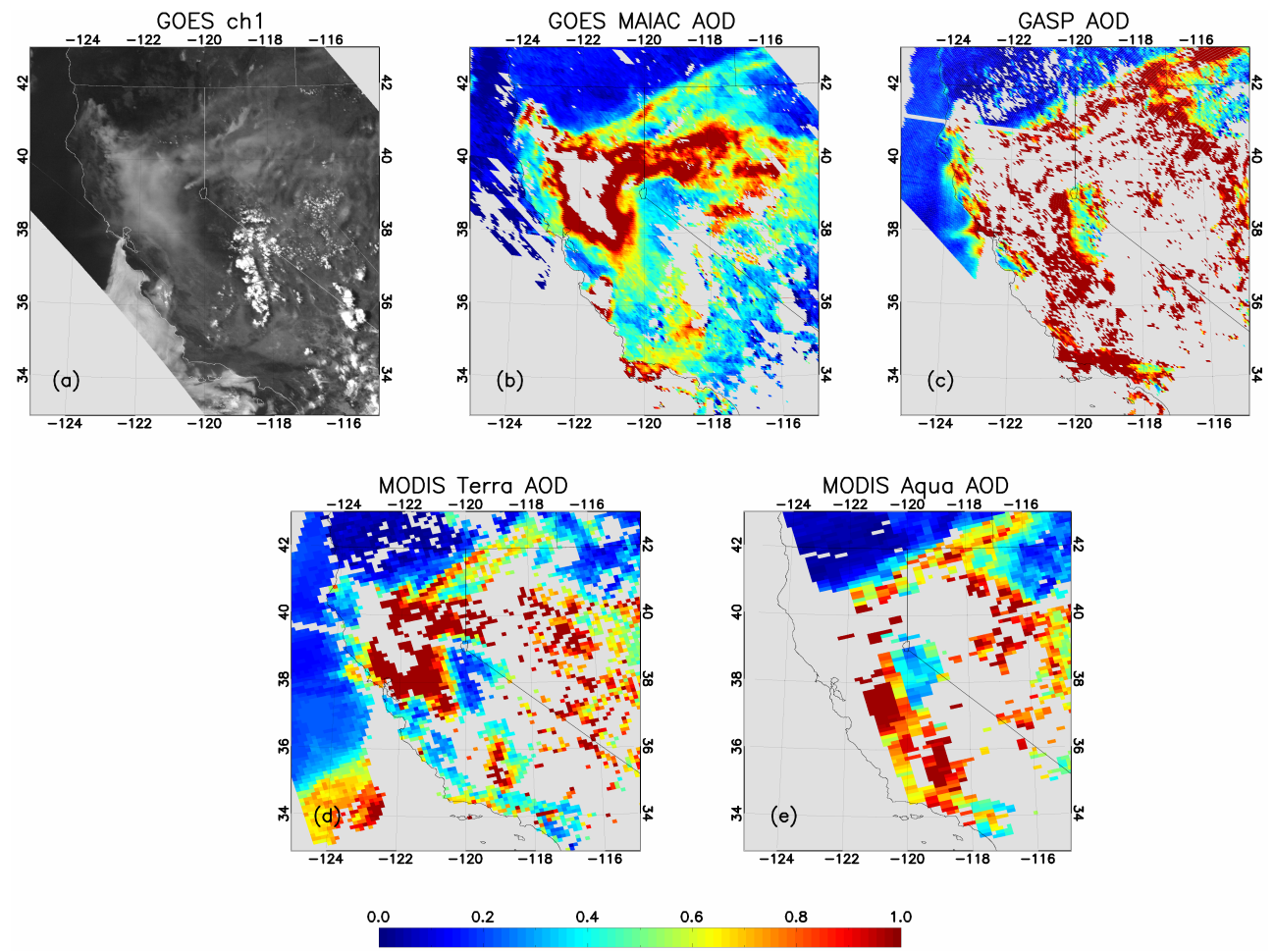

Fig. 11. GOES channel 1 image, AOD retrievals from GOES and MODIS for California fire on 10 July 2008. (a) GOES channel 1 image at 21:45 UTC; (b) MAIAC AOD retrieval at 21:45 UTC; (c) GASP AOD retrieval at 21:45 UTC; (d) MODIS Terra AOD retrieval; (e) MODIS Aqua AOD retrieval.
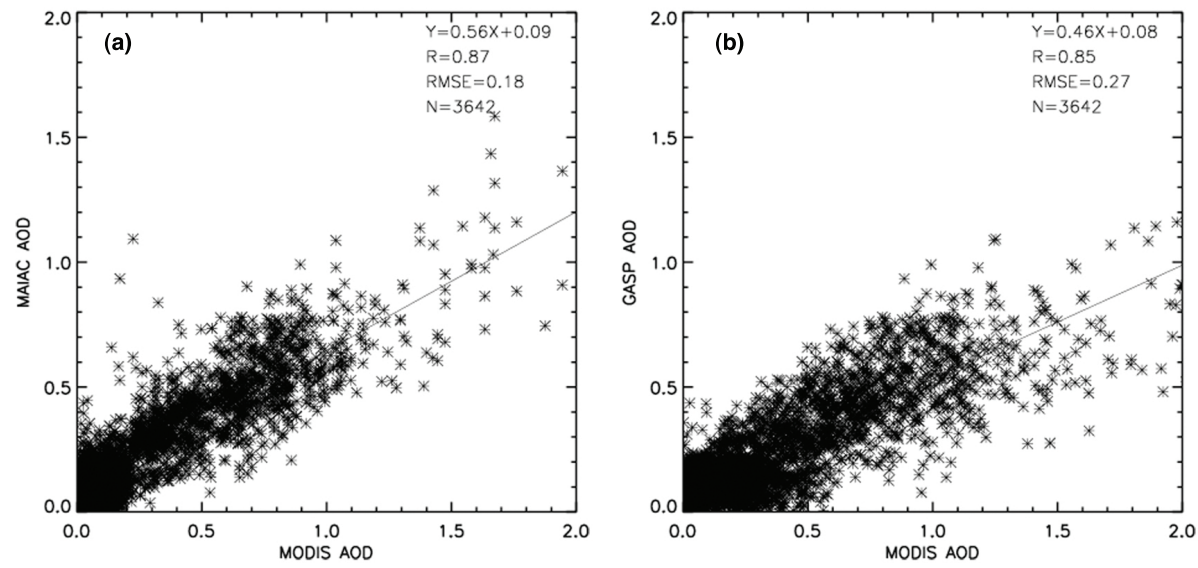

Fig. 12. Scatter plot of GOES AOD vs. MODIS AOD from Aqua for the California fire on 10 July 2008 at Aqua overpass time. (a) MAIAC AOD vs. MODIS AOD from Aqua; (b) GASP AOD vs. MODIS AOD from Aqua.

surface reflectance using GOES images from a much shorter period of time than the operational GASP algorithm, which uses 28-day composites to obtain surface reflectance. The algorithm is validated by comparing with the AERONET and GASP AOD retrievals at six AERONET sites across continental US. MAIAC AOD compares good with AERONET AOD at two western US sites, i.e. Railroad Valley and UCSB, and is better than GASP retrievals at these sites. At the other four eastern and central sites, MAIAC algorithm has similar retrieval accuracy with GASP. This is due to the relative large variations of surface BRDF caused by the precipitation and vegetation change in the eastern and central area. Assuming BRDF shape does not change over a season can reduce the accuracy of surface reflectance and AOD retrievals in these areas. The precipitation and vegetation change is much less in the western US so that surface BRDF is relatively stable 
from day to day. Therefore, MAIAC algorithm is especially suitable for arid areas where BRDF variations are small.

MODIS BRDF retrieval error can introduce errors in MAIAC retrieval. Such uncertainty occurs because the ranges of the sampling geometries of MODIS in a season and GOES over diurnal cycles are different. This is extremely serious at backscatter position where we observed large AOD retrieval errors, hence we filter out the AOD retrievals at such geometry. Such problem will not exist if MAIAC algorithm is applied to the data from GOES-R satellite, which is planned to be launched in 2015. GOES-R ABI (Advanced Baseline Imager) (Schmit et al., 2005) contains blue, red and SWIR $(2.12 \mu \mathrm{m})$ channels similar to those of MODIS. Using this data, $2.12 \mu \mathrm{m}$ BRDF can be retrieved directly without using seasonal average BRDF.

We do not address other sources of uncertainties in the new algorithm, which also exist in GASP. These uncertainty sources include fixed aerosol model, radiometric calibration accuracy of GOES channel 1, and cloud contamination issue, etc. Such uncertainties can also reduce AOD retrieval accuracy and reduce the improvements of the MAIAC algorithm over GASP.

The half-hourly temporal resolution of GOES AOD retrieval is especially useful for air quality monitoring of events with rapid development and motion such as smoke and pollution transport. Although MAIAC for MODIS also can retrieve accurate AOD over western US, it only provides twice daily retrievals. It is hard for air quality forecasters and researchers to tell the aerosol motion from these two snapshots from MODIS AOD retrievals. With the help of the animation of half-hourly GOES AOD retrieval imagery, air quality forecaster and researchers can easily tell the motion of the aerosols. On the other hand, due to the block of cloud, it is possible that none of the two MODIS instruments have retrievals in some areas at the times of the satellites passes. At some other times during the day, the cloud may move out and the areas are clear to be observed by the geostationary satellites. Thus, high temporal observation from geostationary satellite can also improve daily AOD retrieval spatial coverage which cannot be achieved by polar-orbiting satellites with low temporal resolution.

Acknowledgements. This work is supported by the NOAA GOES-R risk reduction program grant NA08NES4280023, NA09NES4400010, and NA10NES4280014.

Edited by: B. Mayer

\section{References}

Al-Saadi, J., Szy kman, J., Pierce, R. B., Kittaka, C., Neil, D., Chu, D. A., Remer, L., Gumley, L., Prins, E., Weinstock, L., MacDonald, C., Wayland, R., Dimmick, F., and Fishman, J.: Improving National Air Quality Forecasts with Satellite Aerosol Observations, B. Am. Meteorol. Soc., 86, 1249-1261, 2005.
Anderson, T. L., Charlson, R. J., Winker, D. M., Ogren, J. A., and Holmen, K.: Mesoscale variations of tropospheric aerosols, J. Atmos. Sci., 60, 119-136, 2003.

Charlson, R. J., Schwartz, S. E., Hales, J. M., Cess, R. D., Coakley, J. A., Hansen, J. E., and Hoffman, D. J.: Climate forcing by anthropogenesis aerosols, Science, 255, 423-430, 1992.

Chow, J. C., Watson, J. G., Mauderly, J. L., Costa, D. L., Wyzga, R. E., Vedal, S., Hidy, G. M., Altshuler, S. L., Marrack, D., Heuss, J. M., Wolff, G. T., Pope III, C. A., and Dockery, D. W.: Health effects of fine particulate air pollution: lines that connect critical review discussion, J. Air Waste Manage. Assoc., 56, 1368-1380, 2006.

GOES I-M databook, http://goes.gsfc.nasa.gov/text/goes.databook. html, 1996, last access: 9 June 2009.

Deuzé, J. L., Bréon, F. M., Devaux, C., Goloub, P., Herman, M., Lafrance, B., Maignan, F., Marchand, A., Nadal, F., Perry, G., and Tanré, D.: Remote sensing of aerosol over land surfaces from POLDER-ADEOS-1 polarized measurements, J. Geophys. Res., 106, 4913-4926, doi:10.1029/2000JD900364, 2001.

Drury, E., Jacob, D. J., Wang, J., Spurrs, R. J. D., and Chance, K.: Improved algorithm for MODIS satellite retrievals of aerosol optical depths over land, J. Geophys. Res., 113, D16204, doi:10.1029/2007JD009573, 2008.

Fraser, R. and Kaufman, Y. J.: The relative importance of aerosol scattering and absorption in remote sensing, Trans. Geosci. Remote Sens., GE-23, 625-633, 1985.

Hauser, A., Oesch, D., Foppa, N., and Wunderle, S.: NOAA AVHRR derived aerosol optical depth over land, J. Geophys. Res., 110, D08204, doi:10.1029/2004JD005439, 2005.

Heidinger, A. K., Anne, V. R., and Dean, C.: Using MODIS to estimate cloud contamination of the AVHRR data record, J. Atmos. Ocean. Technol., 19, 586-601, 2001.

Critical review discussion: Remote sensing of particulate pollution from space: Have we reached the promised land?, J.Air. Waste Manage. Assoc., 59, 1130-1139, doi:10.3155/10473289.59.10.1130, 2009.

Hoff, R. M. and Christopher, S. A. Critical Review - Remote sensing of particulate pollution from space: Have we reached the promised land? A critical review, J. Air. Waste Manage. Assoc., 59, 645-675, doi:10.3155/1047-3289.59.6.645, 2009.

Holben, B. N., Eck, T. F., Slutsker, I., Tanré, Buis, J. P., Setzer, A., Vermote, E., Reagan, J. A., Kaufman, Y. J., Nakajima, T., Lavenu, F., Jankowiak, I., and Smirnov, A.: AERONET: A federated instrument network and data archive for aerosol characterization, Remote Sens. Environ., 66, 1-16, 1998.

Intergovernmental Panel on Climate Change: Climate Change 2007: The Physical Science Basis, Cambridge Univ. Press, Cambridge, UK, 996 pp., 2007.

Kaufman, Y. J.: Satellite sensing of aerosol absorption, J. Geophys. Res., 92, 4307-4317, 1987.

Kaufman, Y. J., Tanré, D., Remer, L. A., Vermote, E. F., Chu, D., and Holben, B. N. : Operational remote sensing of tropospheric aerosol over the land from EOS-MODIS, J. Geophys. Res., 102, 17051-17061, 1997.

Kiehl, J. T. and Briegleb, B. P.: The radiative roles of sulfate aerosols and greenhouse gases in climate forcing, Science, 260, 311-314, 1993.

Knapp, K., Von der Haar, T., and Kaufman, Y.: Aerosol optical depth retrieval from GOES-8: uncertainty study and retrieval 
validation over South America, J. Geophys. Res., 107, 4055, doi:10.1029/2001JD000505, 2002.

Knapp, K. R., Frouin, R., Kondragunta, S., and Prados, A.: Toward aerosol optical depth retrievals over land from GOES visible radiances: determining surface reflectance, Int. J. Remote Sens., 26, 4097-4116, doi:10.1080/01431160500099329, 2005.

Lau, K.-M., Ramanathan, V., Wu, G.-X., Li, Z., Tsay, S. C., Hsu, C., Sikka, R., Holben, B., Lu, D., Tartari, G., Chin, M., Koudelova, P., Chen, H., Ma, Y., Huang, J, Taniguchi, K, Zhang, R: The joint aerosol monsoon experiment, A New Challenge for Monsoon Climate Research, 89, 369, doi:10.1175/BAMS-89-3-369, 2008.

Levy, R. C., Remer, L. A., Mattoo, S., Vermote, E. F., and Kaufman, Y. J.: Second-generation operational algorithm: retrieval of aerosol properties over land from inversion of Moderate Resolution Imaging Spectroradiometer spectral reflectance, J. Geophys. Res., 112, D13211, doi:10.1029/2006JD007811, 2007.

Lohmann, U. and Feichter, J.: Global indirect aerosol effects: A review, Atmos. Chem. Phys., 5, 715-737, doi:10.5194/acp-5-7152005, 2005.

Lucht, W., Schaaf, C. B., and Strahler, A. H.: An algorithm for the retrieval of albedo from space using semiempirical BRDF models, IEEE Trans. Geosci. Remote Sens., 38, 977-998, 2000.

Lyapustin, A. and Knyazikhin, Y.: Green's function method in the radiative transfer problem. I: Homogeneous non-Lambertian surface, Appl. Optics, 50, 3495-3501, 2001

Lyapustin, A. and Wang, Y.: Parameterized code Sharm-3D for radiative transfer over inhomogeneous surfaces, Appl. Optics, 55, 7602-7610, 2005.

Lyapustin, A. and Wang, Y.: MAIAC: multi-angle implementation of atmospheric correction for MODIS, algorithm theoretical basis document (ver. 1.0), 2008.

Lyapustin, A., and Wang, Y. : The time series technique for aerosol retrievals over land from MODIS. In A. Kokhanovky \& G. De Leeuw (Eds.), Satellite aerosol remote sensing over land, 69-99, Springer Praxis Books ISBN978-3-540-69396-3, 2009.

Lyapustin, A., Martonchik, J., Wang, Y., Laszlo, I., and Korkin, S.: Multiangle implementation of atmospheric correction (MAIAC): 1. Radiative transfer basis and look-up tables, J. Geophys. Res., 116, D03210, doi:10.1029/2010JD014985, 2011.

Lyapustin, A., Wang, Y., Laszlo, I., Kahn, R., Korkin, S., Remer, L., Levy, R., and Reid, J. S.: Multiangle implementation of atmospheric correction (MAIAC): 2. Aerosol algorithm, J. Geophys. Res., 116, D03211, doi:10.1029/2010JD014986, 2011.

Martins, J. V., Tanré, D., Remer, L., Kaufman, Y., Mattoo, S. and Levy, R.: MODIS Cloud screening for remote sensing of aerosols over oceans using spatial variability, Geophys. Res. Lett., 29, 8009, doi:10.1029/2001GL013252, 2002.

Martonchik, J. V., Diner, D. J., Kahn, R. A., Ackerman, T. P., Verstraete, M. E., Pinty, B., and Gordon, H. R.: Techniques for the retrieval of aerosol properties over land and ocean using multiangle imaging, IEEE Trans. Geosci. Remote Sens., 36, 1212-1227, 1998.

Pope III, C. A., Burnett, R. T., Thun, M. J., Calle, E. E., Krewski, D., Ito, K., and Thurston, G. D.: Lung cancer, cardiopulmonary mortality and long-term exposure to fine particulate air pollution. J. Amer. Med. Assoc., 287, 1132-1141, 2002.
Pope III, C. A. and Dockery, D. W.: Health effects of fine particulate air pollution: lines that connect, J. Air. Waste Manage. Assoc., 56, 709-742, 2006.

Pope III, C. A.,, Ezzati, M., and Dockery, D. W.: Fine-particulate air pollution and life expectancy in the United States, N. Engl. J. Med., 360, 376-386, 2009.

Popp, C., Hauser, A., Foppa, N., and Wunderle, S.: Remote sensing of aerosol optical depth over central Europe from MSG-SEVIRI data and accuracy assessment with ground-based AERONET measurements, J. Geophys. Res., 112, D24S11, doi:10.1029/2007JD008423, 2007.

Prados, A. I., Kondragunta, S., Ciren, P., and Knapp, K. R.: GOES Aerosol/Smoke Product (GASP) over North America: Comparisons to AERONET and MODIS observations, J. Geophys. Res., 112, D15201, doi:10.1029/2006JD007968, 2007.

Ramanathan, V., Crutzen, P. J., Kiehl, J. T., and Rosenfeld, D.:Aerosols, climate and the hydrological cycle, Science, 294, 2119-2124, 2001.

Rosenfeld, D., Lohmann, U., Raga, G. B., O’Dowd, C. D., Kulmala, M., Fuzzi, S., Reissell, A., and Andreae, M. O.: Flood or Drought: How Do Aerosols Affect Precipitation?, 321, 1309, doi:10.1126/science.1160606, 2008.

Roujean, J.-L., Leroy, M., and Deschamps, P. Y.: A bidirectional reflectance model of the Earth's surface for the correction of remote sensing data, J. Geophys. Res., 97, 20455-20468, 1992.

Schmit, T. J., Gunshor, M. M., Menzel, W. P., Gurka, J. J., Li, J., Bachmeier, A. S.: Introducing the Next-generation Advanced Baseline Imager on GOES-R, Bull. Amer. Meteor. Soc., 86, 1079-1096, 2005.

Stowe, L. L., Davis, P. A., and McClain, E. P.: Scientific basis and initial evaluation of CLAVR-1 global clear/cloud classification algorithm for the advanced very high resolution radiometer, J. Atmos. Oceanic Technol., 16, 656-681, 1999.

Tanré, D., Kaufman, Y. J., Herman, M., and Matteo, S.: Remote sensing of aerosol properties over ocean using the EOS-MODIS spectral radiances, J. Geophys. Res., 102, 16971-16988, 1997.

Vermote, E. F., Tanré, D., Deuzé, J. L., Herman, M., and Morcrette, J. J.: Second simulation of the satellite signal in the solar spectrum, 6S: an overview, IEEE Trans. Geosci. Remote Sens. 35, 675-686, 1997.

Vermote, E. F. and Kotchenova, S.: Atmospheric correction for the monitoring of land surfaces, J. Geophys. Res., 113, D23S90, doi:10.1029/2007JD009662, 2008.

Yuan, T., Remer, L., Pickering, K. E., and Yu, H.: Observational evidence of aerosol enhancement of lightning activity and convective invigoration Geophys. Res. Lett., 38, L04701, doi:10.1029/2010GL046052, 2011.

Zhang, J., Christopher, S. A., and Holben, B. N.: Intercomparison of aerosol optical thickness derived from GOES-8 Imager and Ground-Based Sun Photometers, J. Geophys. Res.-Atmos., 106, 7387-7398, 2001.

Zhang, H., Hoff, R. M., McCann, K., Ciren, P., Kondragunta, S., and Prados, A.: Influence of the ozone and water vapor on the GOES Aerosol and Smoke Product (GASP) retrieval, NOAA Technical report NESDIS 128, 2008. 